\title{
Bacterial profile of infant feces associated with lactation infectious breasts
}

\author{
Yuko Tsunoda' \\ Takashi Asahara ${ }^{2}$ \\ Koji Nomoto ${ }^{3}$ \\ Yukiko Yoshioka ${ }^{4}$ \\ Eisuke Fukuma' \\ 'Department of Breast Surgery, Breast \\ Center, Kameda Medical Center, \\ Kamogawa, Chiba 296-8602, Japan; \\ ${ }^{2}$ Department of Microbiological \\ Research, Yakult Central Institute, \\ Kunitachi, Tokyo I86-8650, \\ Japan; ${ }^{3}$ Department of Molecular \\ Microbiology, Tokyo University of \\ Agriculture, Setagaya-ku, Tokyo I56- \\ 8502, Japan; ${ }^{4}$ Department of Breast \\ Management Research, Oketani Breast \\ Management Research Institute, \\ Shinjuku-ku, Tokyo I62-0044, Japan
}

Correspondence: Yuko Tsunoda Breast Center, Kameda Medical Center 929 Higashi-cho Kamogawa, Chiba 2968602, Japan

$\mathrm{Tel}+8 \mid 470922211$

Fax +81470991198

Email tsunoda.yuko@kameda.jp
This article was published in the following Dove Press journal: Pediatric Health, Medicine and Therapeutics

Background: Mastitis is a common complication in lactating women. However, the diversity of intestinal bacteria in infant exclusively fed infectious milk remains uncharacterized. Our colleagues recently established a method based on 16S and 23S rRNA-targeted reverse transcription-quantitative PCR (RT-qPCR) for detecting bacteria.

Materials and methods: In the present study, the bacteria present in 14 samples of milk and infant feces were characterized using the RT-qPCR method, and concentrations of fecal organic acids were measured during the period of breast massage using HPLC.

Results: Streptococcus agalactiae and Str. parasanguinis were detected in milk from mastitis patients, whereas Str. salivarius and Str. thermophilus were the predominant bacteria in milk from engorged breasts. In feces of breastfed infants, Str. salivarius, Str. thermophiles, and Str. parasanguinis were isolated. Levels of lactate were high in fecal samples, whereas the $\mathrm{pH}$ of infant feces stabilized during breast massage. The bacterial diversity of milk from lactation infectious breasts was similar to that in feces of infant fed milk from lactation infectious breasts. Streptococcus species isolated from the feces of breastfed infants are related to oral cavity health. Conclusion: These results suggest that Streptococcus species, which are part of the healthy oral microflora, may play an important role in preserving the intestinal bacterial flora in infants fed infectious milk.

Keywords: infant feces, infectious breast milk, intestinal bacteria flora, Streptococcus species, fecal organic acids

\section{Introduction}

Breast milk provides nutrition and exerts anti-infectious effects in infants. Although human breast milk is traditionally considered sterile, recent studies have demonstrated that milk of healthy women has a normal microbiota. Species of Staphylococcus, Streptococcus, Lactobacillus, and Bifidobacterium are prevalent in breast milk. ${ }^{1,2}$ Breast milk affects the establishment of the microbiota of the mouth and the gut of infants. ${ }^{3,4}$ Mastitis is an inflammatory disease that commonly occurs during lactation and causes a reduction in the milk supply. Breast massage is a technique widely performed to resolve breastfeeding complications associated with engorgement, plugged ducts, and mastitis. Generally, it is recommended that a mother continue breastfeeding, even if she has signs of mastitis, because it is believed that this does not pose a risk to the infant. ${ }^{5}$ Species of the genus Staphylococcus were found to be the predominant bacteria in human mastitis. Increases in $S$. aureus in milk can cause acute mastitis, whereas high numbers of $S$. epidermidis are associated with subacute mastitis. ${ }^{6,7}$ Both $S$. aureus and Streptococcus agalactiae are etiologic organisms in infections occurring during the early neonatal period. ${ }^{8,9}$ 
The recent development of culture-independent molecular techniques, particularly those based on 16S rRNA genes, has allowed a more complete assessment of the biodiversity of milk and the intestinal microbiota. ${ }^{6,10}$ In a previous study using subgroup- or species-specific primer sets targeting $16 \mathrm{~S}$ or $23 \mathrm{~S}$ rRNA genes from Enterococcus, Streptococcus, and Lactobacillus species, we were able to quantify the target populations with detection limits of $10^{3}-10^{4}$ cells per gram of feces, a sensitivity more than 100 times greater than that of qPCR analyses. This rRNA-targeted reverse transcription-quantitative PCR (RT-qPCR) method enabled the accurate and sensitive differentiation of a diverse array of bacterial groups. ${ }^{11}$

The aim of this study was to compare the species isolated from breast milk of women with lactation infections with species in the feces of their breastfeeding infants using our 16S/23S rRNA RT-qPCR method. In addition, organic acids derived from infant feces were analyzed using HPLC, and the $\mathrm{pH}$ of feces of infants fed milk from women treated with breast massage was also measured.

\section{Materials and methods Study design}

This prospective study was conducted between July 2013 and March 2015 and was approved by the ethics committee of Kameda Medical Center (10-065). All mothers of participants gave written informed consent. Fourteen breastfeeding women with mastitis and their infants were enrolled. The median age of the mothers was 32 years (range, 20-40 years). The women had symptoms of acute inflammation, such as breast pain, erythema, warmth, and induration. They were diagnosed by the attending lactation nurses at Oketani Breast Management Research Institute, and therapeutic breast massage was performed by the nurses in the breast care center during the lactation period. Women with bilateral mastitis or mammary abscesses and women taking antibiotics were excluded from the study. Only infants exclusively fed breast milk were included. Clinical data for women and their infants were collected at enrollment. Breast massage was employed once each day, with a massage duration of at least 10 minutes.

For each woman, samples of breast milk were collected from sites of both mastitis and engorgement. Milk was sampled before the first and the final massage, as follows. Samples $(5-10 \mathrm{~mL})$ were obtained following cleaning of the nipple and areola using a sterile swab after wiping with sterile water by breast care nurses wearing sterile gloves. Fecal samples were collected by both the mothers and the breast care nurses. A spoonful of fecal sample (approximately $0.5 \mathrm{~g}$ ) was placed into each collection tube immediately after the child had defecated. All samples were collected in the breast care center and kept at $4{ }^{\circ} \mathrm{C}$ in a cooling box with refrigerants during shipment to the Kameda Medical Center. The samples were then labeled and stored at $-20^{\circ} \mathrm{C}$ in a refrigerator. Each sample with a case number was kept at $4^{\circ} \mathrm{C}$ in a cooling box and sent to the Yakult Central Institute. All data were collected and managed at the Kameda Medical Center. This study was carried out in accordance with the principles of the Declaration of Helsinki.

\section{Primary treatment of samples}

Milk samples were centrifuged at $12,000 \times g$ for 5 minutes at $4^{\circ} \mathrm{C}$, and the supernatant was decanted and discarded. The pellet was then stored at $-80^{\circ} \mathrm{C}$ until RNA extraction. Fecal samples were weighed, diluted tenfold by addition of RNAlater (v/w), and then homogenized using a Shake Master Auto Ver2.0 (Bio Medical Science Co., Tokyo, Japan). Next, $40 \mu \mathrm{L}$ of the fecal homogenate was transferred into a $2 \mathrm{~mL}$ screw-cap microtube and centrifuged at $12,000 \times g$ for 5 minutes at $4^{\circ} \mathrm{C}$, after which the supernatant was decanted and discarded. The pellet was stored at $-80^{\circ} \mathrm{C}$ until RNA extraction. Primary sample treatment for the quantification of fecal organic acids was performed as follows: fecal samples were weighed, homogenized in 4 volumes of $0.15 \mu \mathrm{mol} / \mathrm{L}$ perchloric acid, and allowed to stand at $4^{\circ} \mathrm{C}$ for 12 hours.

\section{RNA extraction and RT-qPCR}

To quantify the bacteria present in milk and feces samples, total RNA was extracted using a previously described method..$^{3,12,13}$ The microbiota composition was determined using 16S rRNA-targeted RT-qPCR with a Yakult Intestinal Flora-SCAN system (YIF-SCAN ${ }^{\circledR}$ ). Three serial dilutions of the extracted RNA samples were used for bacterial rRNAtargeted RT-qPCR analyses, ${ }^{3,12,13}$ and the threshold cycle values in the linear range of the assay were applied to the standard curve to obtain the corresponding bacterial cell count for each nucleic acid sample. Those data were then used to determine the number of bacteria per sample.

\section{Sequencing of RT-PCR-amplified rRNA genes}

The sequence homology of the rRNA genes among bacteria isolated from the samples was determined using $16 \mathrm{~S}$ and 23S rRNA gene fragments. RT-qPCR products amplified using the $\mathrm{g}-\mathrm{Str}-\mathrm{F} / \mathrm{g}$-Str-R primer set were purified using a High-Pure PCR Product Purification Kit (Hoffman-La Roche Ltd., Basel, Switzerland). The sequences were automatically 
analyzed on an ABI PRISM 3130 genetic analyzer (Thermo Fisher Scientific, Waltham, MA, USA). The resulting rRNA gene sequences were analyzed using the BLAST program of the DNA Data Bank of Japan (http://blast.ddbj.nig.ac.jp/) to assign each strain to a particular species.

\section{Identification and quantification of fecal organic acids}

The fecal suspension was centrifuged at $20,400 \times g$ at $4^{\circ} \mathrm{C}$ for 10 minutes. The supernatant was then filtered through a membrane filter with a pore size of $0.45 \mu \mathrm{m}$ (EMD Millipore, Billerica, MA, USA). Organic acids were analyzed by HPLC using a Waters system (Waters 432 conductivity detector; Waters, Milford, MA, USA) equipped with two columns (Shodex RSpack KC-811, column size: $8 \times 300$ $\mathrm{mm}$; Showa Denko Co. Ltd., Tokyo, Japan). The concentrations of organic acids were normalized against those of an external standard mixture composed of succinic acid, lactic acid, formic acid, acetic acid, propionic acid, butyric acid, iso-valeric acid, and valeric acid. The total concentration of organic acids was determined as the sum of the concentrations of the individual acids.

\section{Fecal $\mathrm{pH}$ measurement}

The $\mathrm{pH}$ of each experimental feces specimen was measured by directly inserting the glass electrode of a D-51 pH meter (Horiba Seisakusho Co., Ltd., Tokyo, Japan) into the homogenized feces.

\section{Statistical analyses}

Results are expressed as mean $\pm \mathrm{SD}$, unless otherwise stated. The log-transformed bacterial counts of milk and feces samples were used for the statistical analyses. Logarithmic transformation was not applied to fecal $\mathrm{pH}$ and organic acid concentration data. Differences in the bacterial counts between the milk obtained from engorgement and mastitis sites were assessed using the Mann-Whitney U-test. Differences in the bacterial counts of milk and feces and differences in the levels of organic acids and fecal $\mathrm{pH}$ during breast massage were analyzed using the Wilcoxon signed-rank sum test. Statistical analyses were performed using SPSS 11.0 software (SPSS Inc., Chicago, IL, USA). $P<0.05$ was considered indicative of statistical significance.

\section{Results}

\section{Characteristics of the subjects}

Milk samples were collected from 14 women with mastitis. The breast opposite the breast with mastitis was engorged in all enrolled women. The median age of the mothers was 32 years (range, 20-40 years). The median axillary temperature before the first massage of the mastitis site was $38.2^{\circ} \mathrm{C}$ (range, $37.1^{\circ} \mathrm{C}-39.7^{\circ} \mathrm{C}$ ), and the median axillary temperature of the engorgement site was $38.0^{\circ} \mathrm{C}$ (range, $35.9^{\circ} \mathrm{C}-39.0^{\circ} \mathrm{C}$ ). All bilateral axillary temperatures before the final breast massage decreased to below $37.0^{\circ} \mathrm{C}$. The median frequency of breast massage was 3.5 times (range, 1-10), and the median duration of massage was 30 minutes (range, 10-60 minutes). Milk was sampled before the first and final massages, with a median interval of 7.5 days (range, 5-20 days). Fecal samples were collected from 14 infants exclusively fed breast milk. The median age of the infants was 2.5 months (range, $1-5$ months). Eleven of the infants were male, and three infants were female. The fecal consistency was soft, muddy, and liquid in nine, three, and two infants, respectively. That consistency did not change during breast massage (Table 1).

\section{Identification of milk bacteria}

The bacteria identified in the breast milk are shown in Table 2. The prevalence of bacteria in milk obtained from either breast site before and after massage was high for Streptococcus and Staphylococcus. Clostridium perfringens, Enterococcus, and Pseudomonas were not detected in any of the milk samples. The counts of Streptococcus in the samples obtained from engorgement and mastitis sites before massage were significantly higher than those of Staphylococcus ( $P=0.001$ and $<0.0001$, respectively). After massage, the counts of Streptococcus in the samples

Table I Clinical characteristics of lactation mastitis mothers and their infants

\begin{tabular}{|l|l|}
\hline Variables & Subjects \\
\hline Mothers $(\mathrm{n}=14)$ & \\
Age (years) & $32(20-40)$ \\
Axillary temperature $\left({ }^{\circ} \mathrm{C}\right)$ & $38.2(37.1-39.7)$ \\
$\quad$ Mastitis site & $38.0(35.9-39.0)$ \\
$\quad$ Engorgement site & $3.5(\mathrm{I}-10)$ \\
Frequency of breast massage (times) & $7.5(5-20)$ \\
Interval of milk sampling (days) & \\
Infants ( $\mathrm{n}=14)$ & $2.5(\mathrm{I}-5)$ \\
Age (months) & \\
Gender & $\mathrm{II}$ \\
Male & 3 \\
Female & \\
Fecal consistency & 9 \\
Soft & 3 \\
Muddy & 2 \\
$\quad$ Liquid &
\end{tabular}

Note: Data are expressed as median and range. 
Table 2 Change in counts of bacteria in milk during breast massage

\begin{tabular}{|c|c|c|c|c|c|c|c|c|}
\hline & \multicolumn{2}{|c|}{ Before massage } & & & \multicolumn{2}{|c|}{ After massage } & & \\
\hline & \multicolumn{2}{|c|}{ Engorgement site } & \multicolumn{2}{|c|}{ Mastitis site } & \multicolumn{2}{|c|}{ Engorgement site } & \multicolumn{2}{|c|}{ Mastitis site } \\
\hline & $\begin{array}{l}\log _{10} \\
\text { cells } / \mathrm{mL}\end{array}$ & Prevalence & $\begin{array}{l}\log _{10} \\
\text { cells } / \mathrm{mL}\end{array}$ & Prevalence & $\begin{array}{l}\log _{10} \text { cells } / \\
\mathrm{mL}\end{array}$ & Prevalence & $\begin{array}{l}\log _{10} \\
\text { cells } / \mathrm{mL}\end{array}$ & Prevalence \\
\hline Clostridium coccoides group & ND & & ND & & ND & & 0.3 & $1 / 14$ \\
\hline C. leptum subgroup & ND & & 0.8 & $1 / 14$ & I & $1 / 14$ & 0.5 & \\
\hline Bacteroides fragilis group & ND & & ND & $1 / 14$ & ND & & ND & \\
\hline Bifidobacterium & 1.6 & $2 / 14$ & $2.2 \pm 0.5^{\mathrm{a}}$ & $3 / 14$ & 1.3 & $2 / 14$ & $2.2 \pm 0.3$ & $3 / 14$ \\
\hline Atopobium cluster & 1.5 & $2 / 14$ & 3.1 & $1 / 14$ & 2.3 & $1 / 14$ & 0.7 & $2 / 14$ \\
\hline Prevotella & 2.3 & $1 / 14$ & 2.5 & $1 / 14$ & ND & & 0.7 & $2 / 14$ \\
\hline C. perfringens & ND & & ND & & ND & & ND & \\
\hline Total Lactobacillus & $0.9 \pm 0.3$ & $4 / 14$ & 0.6 & $2 / 14$ & $1.5 \pm 0.9$ & $3 / 14$ & 0.8 & $2 / 14$ \\
\hline Enterobacteriaceae & 0.3 & $1 / 14$ & 0.5 & $1 / 14$ & ND & & 0.6 & $1 / 14$ \\
\hline Enterococcus & ND & & ND & & ND & & ND & \\
\hline Streptococcus & $2.7 \pm 1.0 *$ & $14 / 14$ & $3.3 \pm 1.4^{*}$ & $14 / 14$ & $2.5 \pm 0.9 * / * *$ & $14 / 14$ & $2.7 \pm 0.6 *$ & $14 / 14$ \\
\hline Staphylococcus & $1.5 \pm 0.7$ & $13 / 14$ & $1.6 \pm 1.0$ & $14 / 14$ & $1.3 \pm 0.8$ & $12 / 14$ & $1.6 \pm 0.7$ & $10 / 14$ \\
\hline Pseudomonas & ND & & ND & & ND & & ND & \\
\hline
\end{tabular}

Notes: ${ }^{a}$ Data are expressed as mean and SD. $* P<0.01$, as obtained by comparison with Staphylococcus using the Mann-Whitney $U$-test; $* * P=0.056$, as obtained by comparison with the sample before massage on engorgement site using the Wilcoxon signed-rank test.

Abbreviation: ND, not detected.

from the engorgement and mastitis sites were also significantly higher than those of Staphylococcus $(P<0.0001)$. Regarding the effect of breast massage on bacterial levels, the counts of Streptococcus in milk from the engorgement site decreased after massage, but the difference was not significant $(P=0.056)$. Similarly, the counts of Streptococcus in milk from the mastitis site did not differ before and after massage ( $P=0.198)$.

\section{Identification of intestinal bacteria}

The intestinal bacteria in infant feces samples are shown in Table 3. The total bacterial count before massage was $10 \log _{10}$ cells/g, and that did not change after massage. In pre-massage samples, the counts of Streptococcus were significantly higher than those of Staphylococcus $(P=0.019)$. In the post-massage samples, the counts of Streptococcus were also significantly higher than those of Staphylococcus $(P<0.0001)$. Bifidobacterium, Atopobium cluster, total Lactobacillus, Enterobacteriaceae, Enterococcus, Streptococcus, and Staphylococcus were detected at high prevalence before massage, whereas the Clostridium coccoides group, $C$. leptum subgroup, B. fragilis group, Prevotella, and $C$. perfringens were detected at low prevalence before massage. These distributions in the feces did not change after massage. Pseudomonas was not detected in any fecal samples. The counts of Enterococcus in the feces decreased significantly after massage $(P=0.033)$, whereas the counts of other bacteria in the feces did not change significantly after massage.

\section{Distributions of Streptococcus species isolated from milk and infant fecal samples}

A variety of Streptococcus species were isolated from milk samples. Str. agalactiae and Str. dysgalactiae sub sp. in the pyogenic group were identified in five samples and one sample, respectively. Str. parasanguinis, Str. oralis, Str. dentisani, and Str. pneumoniae in the mitis group were isolated from 4, 13, 4, and 4 samples, respectively. Str. salivarius and Str. thermophilus in the salivarius group were isolated from seven and five samples, respectively. Str. agalactiae and Str. parasanguinis were detected prevalently in the mastitis site. Str. salivarius and Str. thermophilus were the predominant bacteria in the engorgement site (Figure 1A). Various Streptococcus species were isolated from infant feces. Str. salivarius and Str. thermophilus were detected in fecal samples before and after massage, at about $8.0 \log _{10}$ cells/g, Str. parasanguinis was also detected in fecal samples, and the prevalence of this species was higher after massage compared to before massage. Str. oralis was only detected in one fecal sample after massage (Figure 1B).

\section{Fecal organic acids and the $\mathrm{pH}$ of infant feces}

The concentration of total organic acids before and after massage was $81.8 \pm 55.5$ and $102.3 \pm 77.6 \mu \mathrm{mol} / \mathrm{g}$, respectively. The predominant acids detected before massage were lactate and acetate, at concentrations of $34.7 \pm 30.6$ and $37.8 \pm 25.6 \mu \mathrm{mol} / \mathrm{g}$, respectively. The distribution of fecal organic acids after massage was similar to that before massage. No significant 
Table 3 Change in counts of intestinal bacteria in infant feces during breast massage

\begin{tabular}{|l|l|l|l|l|}
\hline \multicolumn{2}{|l|}{ Before massage } & \multicolumn{2}{l|}{ After massage } \\
\hline & $\begin{array}{l}\log _{10} \\
\text { cells/g }\end{array}$ & Prevalence & \multicolumn{2}{l|}{$\begin{array}{l}\log _{10} \\
\text { cells/g }\end{array}$} \\
\hline Total bacteria & $10.0 \pm 0.6^{\mathrm{a}}$ & $14 / 14$ & $9.9 \pm 0.9$ & Prevalence \\
Clostridium coccoides group & $7.7 \pm 1.2$ & $4 / 14$ & $8.0 \pm 0.6$ & $14 / 14$ \\
C. leptum subgroup & 5.7 & $2 / 14$ & 6.3 & $4 / 14$ \\
Bacteroides fragilis group & $9.2 \pm 0.6$ & $3 / 14$ & $9.2 \pm 0.9$ & $2 / 14$ \\
Bifidobacterium & $9.7 \pm 1.2$ & $12 / 14$ & $9.4 \pm 1.7$ & $3 / 14$ \\
Atopobium cluster & $8.1 \pm 1.3$ & $8 / 14$ & $7.6 \pm 0.8$ & $10 / 14$ \\
Prevotella & $5.9 \pm 0.5$ & $5 / 14$ & $5.8 \pm 0.5$ & $8 / 14$ \\
C. perfringens & $6.6 \pm 2.9$ & $3 / 14$ & $6.1 \pm 2.9$ & $7 / 14$ \\
Total Lactobacillus & $5.6 \pm 1.6$ & $9 / 14$ & $6.0 \pm 1.9$ & $3 / 14$ \\
Enterobacteriaceae & $8.1 \pm 1.1$ & $12 / 14$ & $7.9 \pm 1.1$ & $8.2 \pm 1.3 * *$ \\
Enterococcus & $7.8 \pm 1.0$ & $12 / 14$ & $7.6 \pm 0.8 *$ & $12 / 14$ \\
Streptococcus & $8.1 \pm 1.2^{*}$ & $14 / 14$ & $6.5 \pm 0.9$ & $12 / 14$ \\
Staphylococcus & $6.9 \pm 1.1$ & $14 / 14$ & $\mathrm{ND}$ & $14 / 14$ \\
Pseudomonas & $\mathrm{ND}$ & & $14 / 14$ \\
\hline
\end{tabular}

Notes: ${ }^{\mathrm{D} D a t a}$ are expressed as mean and SD. $* P<0.01$, as obtained by comparison with Staphylococcus using the Mann-Whitney U-test; ** $P=0.033$, as obtained by comparison with the sample before massage using the Wilcoxon signed-rank test.

Abbreviation: ND, not detected.

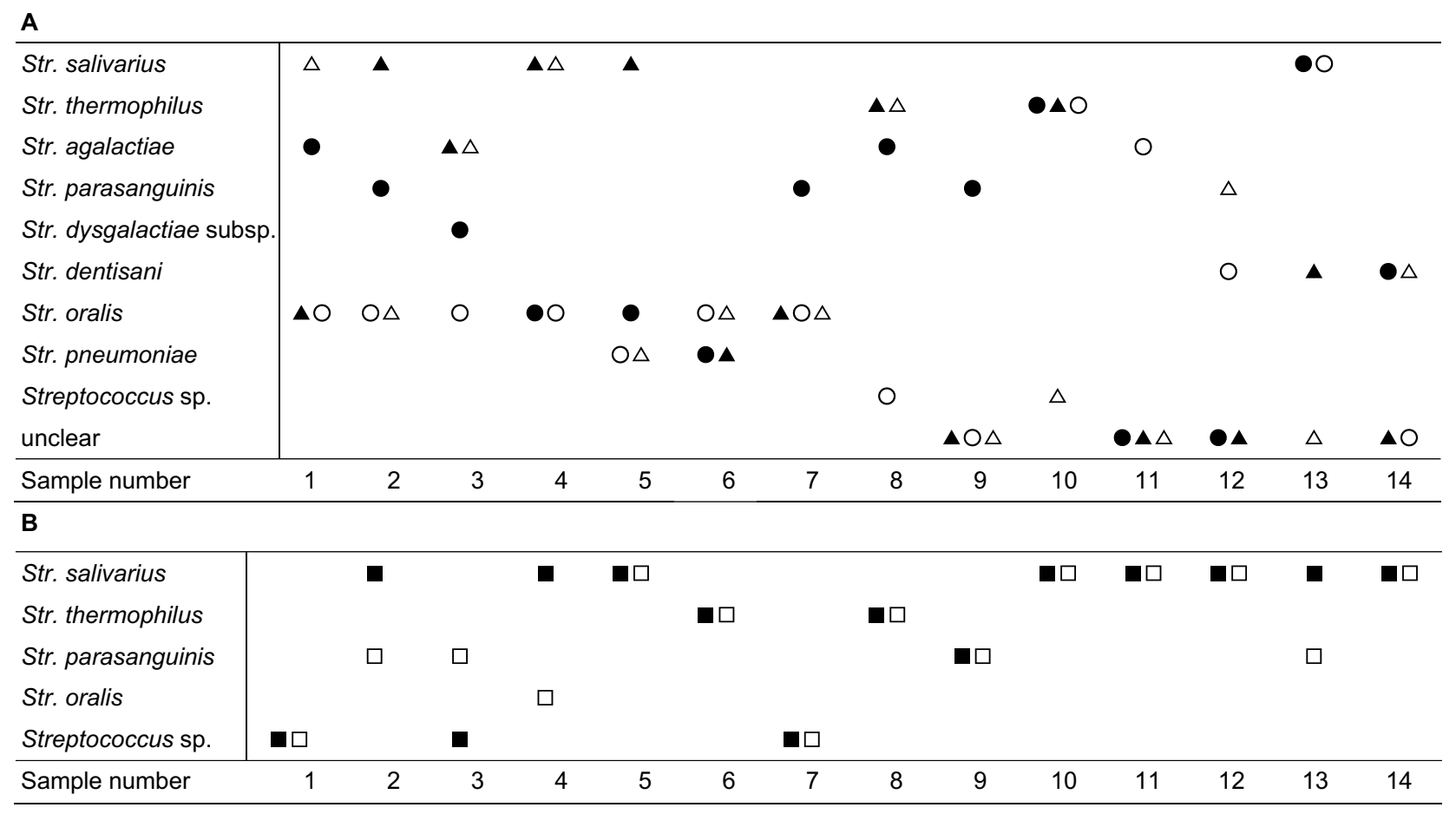

Figure I (A) Distribution of Streptococcus species isolated from the milk samples at mastitis site (before massage, $\mathbf{O}$; after massage, $\bigcirc$ ) and at engorgement site (before massage, $\mathbf{\Delta}$; after massage, $\triangle$ ). (B) Distribution of Streptococcus species isolated from the infant's fecal samples (before massage, $\mathbf{\square}$; after massage, $\square$ ).

changes in the concentrations of fecal organic acids were observed during massage. The fecal $\mathrm{pH}$ was about 5.3 both before and after massage (Table 4).

\section{Discussion}

The etiology of human lactation mastitis involves an increase in the number of bacteria caused by breast milk stasis. ${ }^{6,14}$ The diversity of bacterial communities in milk of engorged breast has not been reported. In this study, milk samples were collected from not only mastitis-affected breasts but also engorged breasts in the same women. Bacteria representing 11 genera and species were identified. The counts of Streptococcus in milk samples from the engorgement sites were significantly higher than those of Staphylococcus, similar to the mastitis sites. After alleviating the infection by breast massage, Streptococcus remained the dominant 
Table 4 Change in fecal organic acids and $\mathrm{pH}$ in infant feces during breast massage

\begin{tabular}{|c|c|c|c|c|c|}
\hline & \multicolumn{2}{|c|}{ Before massage } & \multicolumn{2}{|c|}{ After massage } & \multirow[b]{2}{*}{$P$-value ${ }^{a}$} \\
\hline & $\mu \mathrm{mol} / \mathrm{g}$ & Prevalence & $\mu \mathrm{mol} / \mathrm{g}$ & Prevalence & \\
\hline Total organic acid & $81.8 \pm 55.5^{b}$ & $14 / 14$ & $102.3 \pm 77.6$ & $14 / 14$ & 0.55 \\
\hline Succinic acid & $9.5 \pm 9.6$ & $12 / 14$ & $10.4 \pm 14.1$ & $14 / 14$ & 0.22 \\
\hline Lactic acid & $34.7 \pm 30.6$ & $13 / 14$ & $49.3 \pm 48.6$ & $10 / 14$ & 0.86 \\
\hline Formic acid & $6.1 \pm 6.8$ & $7 / 14$ & $5.7 \pm 3.5$ & $9 / 14$ & 0.39 \\
\hline Acetic acid & $37.8 \pm 25.6$ & $14 / 14$ & $41.9 \pm 35.8$ & $14 / 14$ & 0.83 \\
\hline Propionic acid & $1.2 \pm 1.2$ & $6 / 14$ & $0.7 \pm 0.7$ & $5 / 14$ & 0.21 \\
\hline Butyric acid & ND & & 5.5 & $2 / 14$ & \\
\hline Isovaleric acid & ND & & ND & & \\
\hline Valeric acid & ND & & ND & & \\
\hline $\mathrm{pH}$ & $5.3 \pm 0.7$ & $14 / 14$ & $5.3 \pm 1.0$ & $13 / 14$ & 0.59 \\
\hline
\end{tabular}

Notes: ${ }^{a}$ Wilcoxon signed-rank test was used for the difference in changes of fecal organic acids and $\mathrm{pH}$ during breast massage. ${ }^{\mathrm{b}} \mathrm{Data}$ are expressed as mean and SD. Abbreviation: ND, not detected.

bacteria in milk from both engorged and mastitis-affected sites. Staphylococcus is reportedly the predominant bacteria in human lactation mastitis, with Streptococcus the second most abundant group. ${ }^{6}$ In our series, the median axillary temperature of the engorgement and mastitis sites was $<38.5^{\circ} \mathrm{C}$ before massage and $<37.0^{\circ} \mathrm{C}$ after massage, which suggests that Streptococcus can predominate in milk stasis without causing a severe infection.

Based on 16S rRNA gene sequences, Streptococcus species can be categorized into six groups as follows: pyogenic, anginosus, mutans, mitis, salivarius, and bovis. Str. agalactiae, in the pyogenic group, was first described as a cause of bovine mastitis and is the most common cause of neonatal sepsis. Recently, an association between Str. agalactiae in infectious breast milk and late-onset neonatal infections was reported. ${ }^{15}$ However, signs of infection were not observed in our infants, who were fed milk containing Str. agalactiae. This suggests that Str. agalactiae in milk of mastitis-affected breasts does not necessarily cause infections in healthy breastfed infants. Str. parasanguinis, in the mitis group, is one of the major early colonizers of dental surfaces in humans, and its presence in the oral cavity is associated with development of a healthy microflora by the formation of dental plaque, ${ }^{16}$ whereas although Str. parasanguinis was reportedly isolated from milk of human lactation mastitis, the organism was not significantly associated with the mastitis. ${ }^{6}$ In this study, Str. parasanguinis was detected in milk samples from engorgement sites at counts higher than Staphylococcus. Str. salivarius is known to be a pioneer colonizer of infants, who typically acquire it from their mother shortly after birth. ${ }^{17}$ This species is a prominent member of the oral microbiota in healthy humans and is closely related to Str. thermophilus, ${ }^{18}$ a species that is considered safer than other Streptococcus species and is generally used in the production of yogurt. Str. salivarius and Str. thermophilus were identified in this study as the predominant bacteria in milk from engorgement sites, which suggests that these species may increase in number during the early stage of milk stasis.

Facultative anaerobes such as Enterococcus, Streptococcus, Staphylococcus, Enterobacter, and Escherichia are considered to be the first colonizers of the meconium. ${ }^{19}$ The sources of bacteria transmitted to the infant during the period of microbial variation include the mother's vaginal, gut, and oral microbiota, the skin of caretakers and siblings, and breast milk and other foods. Microbial colonization of the gut is more influenced by early feeding practices than the mode of delivery. ${ }^{3,20}$ Regarding the effect of breast milk on the intestinal microbial flora, several studies have reported that the counts of Bifidobacterium are higher and the counts of Enterobacteriaceae and Bacteroides lower in neonates fed breast milk compared to those fed formula milk..$^{21,22}$ Bifidobacterium is a major member of the normal infant microbiota and is believed to provide health-promoting benefits. ${ }^{23}$ In this study, neither the counts nor the prevalence of Bifidobacterium in the feces of infants fed breast milk by women with mastitis or engorgement that changed significantly after massage were similar to infants fed healthy breast milk in a previous study. ${ }^{3}$ Conversely, in the feces of infants in our study, Enterococcus numbers decreased after breast massage for mastitis. Enterococcus is a member of the normal human intestinal flora and has both an intrinsic and acquired resistance to antibiotics, making it an important nosocomial pathogen. The changes in Bifidobacterium and Enterococcus numbers suggest that homeostasis of the infants' gut bacterial flora was maintained while the clinical symptoms of mastitis were treated with breast massage. 
Breast milk provides nutrition for the infant and is a source of oral bacteria. A previous study demonstrated that qPCR-based detection of Lactobacillus in the oral cavity of infants is consistent with detection of Lactobacillus in breast milk. ${ }^{24}$ Holgerson et al reported that viable Lactobacilli detected in saliva from breastfed infants has an inhibitory effect on oral Streptococcus. ${ }^{4}$ In this study, many of the streptococci detected in infant feces during breast massage, such as Str. salivarius, Str. thermophiles, and Str. parasanguinis, play a role in maintaining oral cavity health. This suggests that Lactobacillus in the saliva of breastfed infants may inhibit the pathogenic streptococci in milk affected by engorgement and mastitis and maintain the healthy bacterial flora of the intestine.

Variations in the microbiota composition of breast milk are known to affect nutrient absorption and energy metabolism in infants, but few studies have examined the association between fecal microbiota and fecal organic acids in infants fed mastitis milk. Under normal conditions, acetate, propionate, and butyrate are the principal organic acids, and lactate is present at low concentrations in the feces of healthy infants. ${ }^{3}$ A previous study showed that the concentration of acetate in infant feces is related to the Bifidobacterium population in the intestine. ${ }^{25}$ Since acetate is the major product of Bifidobacterium fermentation, an increase in acetate in the feces appears to reflect the establishment of Bifidobacterium as the predominant microbiota in infants. ${ }^{3}$ In this study, the concentration of acetate in the feces of infants fed infectious breast milk ( $37 \mu \mathrm{mol} / \mathrm{g})$ was lower than that in healthy infant feces in the previous report $(50 \mu \mathrm{mol} / \mathrm{g}),{ }^{3}$ whereas the counts of Bifidobacterium ( $9.7 \log _{10}$ cells/g) were similar to that in healthy infant feces $\left(9.8 \log _{10}\right.$ cells/g). ${ }^{3}$ Lactobacillus reportedly produces D- or DL-lactate, which contributes to fecal acidosis. ${ }^{26}$ In our infants, who were fed milk from their mothers with engorgement or mastitis, the counts of Lactobacillus in the feces $\left(5.6 \log _{10}\right.$ cells $\left./ \mathrm{g}\right)$ were similar to those in the feces of infants fed milk from healthy women (5.8 $\log _{10}$ cells/g), whereas the concentration of lactate in our study $(34 \mu \mathrm{mol} / \mathrm{g})$ was higher than that in healthy infant feces $(16 \mu \mathrm{mol} / \mathrm{g}){ }^{3}$ Str. salivarius can modulate the intestinal $\mathrm{pH}$ through the hydrolysis of urea, which is upregulated by induction of urease gene expression by acidic $\mathrm{pH} .{ }^{27}$ In our infant feces, Str. salivarius was the predominant species during breast massage, suggesting that the fecal $\mathrm{pH}$ of our samples (5.3 \pm 0.7$)$ was within the normal range of healthy infant feces (5.9 \pm 0.7$).{ }^{3}$ These results suggest that Bifidobacterium, Lactobacillus, and Str. salivarius may play an important role in modulating the metabolic environment in the intestine of breastfed infants, thereby preserving the metabolic balance.

\section{Limitations}

Our study has several limitations. First, only a small group (14 cases) was evaluated. Second, we did not examine the feces of infants after the women had recovered from mastitis. Third, pathogenic Streptococcus species remained in the milk after the breast massage, and trends in the number of pathogenic bacteria over time in infected breasts were not evaluated. To prove the safety of breastfeeding, a further study is necessary, which examines the relationship between intestinal bacterial flora and fecal organic acids in feces of infants fed infectious breast milk in large number group.

\section{Conclusion}

This study demonstrates that the bacterial diversity of milk from engorgement sites was similar to that from mastitis sites in the same women, and the Streptococcus species isolated from the feces of breastfed infants and detected in milk from infectious breasts are related to oral cavity health. Therefore, our results suggest that an increase in the numbers of Streptococcus species may initiate infection, and the intestinal microbiota of breastfed infants may adjust to the environment through organisms derived from the saliva. As Streptococcus species are major constituents of the healthy oral microflora, Str. salivarius may play an important role in preserving the intestinal bacterial flora and the metabolic balance in infants fed infectious milk. As this study has several limitations, further studies are necessary to support this hypothesis.

\section{Acknowledgments}

The authors thank Rie Nogami, Yukiko Shimizu, and Naomi Sakamoto for their assistance with data collection. We thank Dr Akira Tsunoda for his statistical advice.

\section{Disclosure}

The authors report no conflicts of interest in this work.

\section{References}

1. Collado MC, Delgado S, Maldonado A, Rodríguez JM. Assessment of the bacterial diversity of breast milk of healthy women by quantitative real-time PCR. Lett Appl Microbiol. 2009;48(5):523-528.

2. Cabrera-Rubio R, Collado MC, Laitinen K, Salminen S, Isolauri E, Mira A. The human milk microbiome changes over lactation and is shaped by maternal weight and mode of delivery. Am J Clin Nutr. 2012;96(3):544-551.

3. Tsuji H, Oozeer R, Matsuda K, et al. Molecular monitoring of the development of intestinal microbiota in Japanese infants. Benef Microbes. 2012;3(2):113-125.

4. Holgerson PL, Vestman NR, Claesson R, et al. Oral microbial profile discriminates breast-fed from formula-fed infants. $J$ Pediatr Gastroenterol Nutr. 2013;56(2):127-136. 
5. Spencer JP. Management of mastitis in breastfeeding women. Am Fam Physician. 2008;78(6):727-731.

6. Delgado S, Arroyo R, Martín R, Rodríguez JM. PCR-DGGE assessment of the bacterial diversity of breast milk in women with lactational infectious mastitis. BMC Infect Dis. 2008;8:51.

7. Jiménez E, de Andrés J, Manrique M, et al. Metagenomic analysis of milk of healthy and mastitis-suffering women. J Hum Lact. 2015;31(3):406-415.

8. Kayıran PG, Can F, Kayıran SM, Ergonul O, Gürakan B. Transmission of methicillin-sensitive Staphylococcus aureus to a preterm infant through breast milk. J Matern Fetal Neonatal Med. 2014;27(5):527-529.

9. Le Doare K, Kampmann B. Breast milk and Group B streptococcal infection: vector of transmission or vehicle for protection? Vaccine. 2014;32(26):3128-3132.

10. Matsuki T, Watanabe K, Fujimoto J, et al. Quantitative PCR with 16S rRNA-gene-targeted species-specific primers for analysis of human intestinal bifidobacteria. Appl Environ Microbiol. 2004;70(1):167-173.

11. Kubota H, Tsuji H, Matsuda K, Kurakawa T, Asahara T, Nomoto K. Detection of human intestinal catalase-negative, Gram-positive cocci by rRNA-targeted reverse transcription-PCR. Appl Environ Microbiol. 2010;76(16):5440-5451.

12. Matsuda K, Tsuji H, Asahara T, Kado Y, Nomoto K. Sensitive quantitative detection of commensal bacteria by rRNA-targeted reverse transcription-PCR. Appl Environ Microbiol. 2007;73(1):32-39.

13. Matsuda K, Tsuji H, Asahara T, Matsumoto K, Takada T, Nomoto K. Establishment of an analytical system for the human fecal microbiota, based on reverse transcription-quantitative PCR targeting of multicopy rRNA molecules. Appl Environ Microbiol. 2009;75(7):1961-1969.

14. Osterman KL, Rahm VA. Lactation mastitis: bacterial cultivation of breast milk, symptoms, treatment, and outcome. J Hum Lact. 2000;16(4):297-302.

15. Filleron A, Lombard F, Jacquot A, et al. Group B streptococci in milk and late neonatal infections: an analysis of cases in the literature. Arch Dis Child Fetal Neonatal Ed. 2014;99(1):F41-F47.

16. Kolenbrander PE. Oral microbial communities: biofilms, interactions, and genetic systems. Annu Rev Microbiol. 2000;54:413-437.
17. Carlsson J, Grahnén H, Jonsson G, Wikner S. Early establishment of Streptococcus salivarius in the mouth of infants. $J$ Dent Res. 1970;49(2):415-418.

18. Bentley RW, Leigh JA, Collins MD. Intrageneric structure of Streptococcus based on comparative analysis of small-subunit rRNA sequences. Int J Syst Bacteriol. 1991;41(4):487-494.

19. Jiménez E, Marín ML, Martín R, et al. Is meconium from healthy newborns actually sterile? Res Microbiol. 2008;159(3):187-193.

20. Biasucci G, Rubini M, Riboni S, Morelli L, Bessi E, Retetangos C. Mode of delivery affects the bacterial community in the newborn gut. Early Hum Dev. 2010;86(Suppl 1):13-15.

21. Penders J, Thijs C, Vink C, et al. Factors influencing the composition of the intestinal microbiota in early infancy. Pediatrics. 2006;118(2):511-521.

22. Fallani M, Young D, Scott J, et al. Intestinal microbiota of 6-weekold infants across Europe: geographic influence beyond delivery mode, breast-feeding, and antibiotics. J Pediatr Gastroenterol Nutr. 2010;51(1):77-84.

23. Rinne M, Kalliomaki M, Arvilommi H, Salminen S, Isolauri E. Effect of probiotics and breastfeeding on the bifidobacterium and lactobacillus/enterococcus microbiota and humoral immune responses. J Pediatr. 2005;147(2):186-191.

24. Jara S, Sánchez M, vera R, Cofré J, Castro E. The inhibitory activity of Lactobacillus spp. isolated from breast milk on gastrointestinal pathogenic bacteria of nosocomial origin. Anaerobe. 2011;17(6):474-477.

25. Knol J, Scholtens P, Kafka C, et al. Colon microflora in infants fed formula with galacto- and fructo-oligosaccharides: more like breast-fed infants. J Pediatr Gastroenterol Nutr. 2005;40(1):36-42.

26. Kaneko T, Bando Y, Kurihara H, Satomi K, Nonoyama K, Matsuura N. Fecal microflora in a patient with short-bowel syndrome and identification of dominant lactobacilli. J Clin Microbiol. 1997;35(12):3181-3185.

27. Huang SC, Burne RA, Chen YY. The pH-dependent expression of the urease operon in Streptococcus salivarius is mediated by CodY. Appl Environ Microbiol. 2014;80(17):5386-5393.
Pediatric Health, Medicine and Therapeutics

\section{Publish your work in this journal}

Pediatric Health, Medicine and Therapeutics is an international, peerreviewed, open access journal publishing original research, reports, editorials, reviews and commentaries. All aspects of health maintenance, preventative measures and disease treatment interventions are addressed within the journal. Practitioners from all disciplines are invited to submit

\section{Dovepress}

their work as well as healthcare researchers and patient support groups. The manuscript management system is completely online and includes a very quick and fair peer-review system. Visit http://www.dovepress.com/ testimonials.php to read real quotes from published authors. 